\title{
Dynamic responses of reinforced concrete slabs under sudden impact loading
}

Recep Tuğrul Erdem (Main and Corresponding Author)

Department of Civil Engineering, Manisa Celal Bayar University

45140, Manisa (Turkey)

tugrul.erdem@cbu.edu.tr

https://orcid.org/0000-0002-8895-7602

\author{
Manuscript Code: 27885 \\ Date of Acceptance/Reception: 12.08.2021/21.01.2021 \\ DOI: 10.7764/RDLC.20.2.346
}

\begin{abstract}
Reinforced concrete (RC) slabs may be subjected to low-velocity impact effect in their service lives. In this study, it is aimed to investigate dynamic

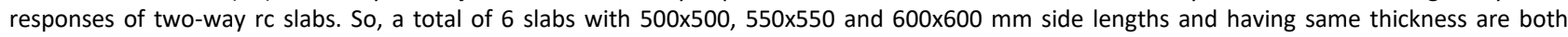
experimentally and numerically investigated under low velocity impact loading. Two different reinforcement configurations are used in the production of each slab. A drop test setup is designed for the experimental study. Besides, measurement devices such as accelerometer, Ivdt, dynamic load cell, data logger and optic photocells are used in the experimental program. Experiments on the specimens are carried out for the same level of impact energy. Acceleration, displacement and impact load values of slabs are presented by time dependent graphs. In addition, cracks and deformations are observed during tests. In the numerical part of this study, a detailed finite element procedure where explicit dynamic analysis is performed by Abaqus finite elements software is established. The simulations are performed for each test specimen under impact effect and analysis results are used in the verification of experimental results. The relationship between experimental and numerical studies is comparatively examined in terms of crack patterns and average ratios of accelerations, displacements, impact loads. Finally, it is considered that the proposed numerical model could be used in the evaluation of experimental results under impact loading.
\end{abstract}

Keywords: drop test setup, impact loading, measurement devices, numerical analysis, rc slab.

Concrete is a widely used construction material that is produced by cement, aggregate, water and chemical additives if necessary. While compressive strength of concrete is high, tensile strength is very low. For this reason, steel reinforcement is placed in tensile regions of structural members with specific ratios. So, both concrete and steel materials act together to resist different loading types. Due to several advantages of rc structural members such as ductility, rigidity, strength, durability, maintenance cost and fire resistance, they are commonly used in the building industry in all over the world.

Slab is one of the most important structural members in the rc structural system. Slabs are planar members which are used to cover areas in constructions. Vertical loads are transferred from slabs to other structural members as columns, shear walls and beams. Rc slabs are designed with the assumption of rigid diaphragm. By this way, lateral loads are distributed to vertical structural members by considering their stiffness values.

Structural members are subjected to different types of loading during their service. Loads can be categorized in 3 main types such as constant, live and dynamic ones. Behavior of structural members under various loads has been an important field of interest by researchers and engineers. However, there aren't many studies in which effect of impact loading is investigated. The main reasons of this situation are difficulties in developing a drop test setup and generating finite element models in the software. Especially, incremental dynamic analysis becomes more complex when studying with inelastic materials as reinforced concrete. So, there are limited numbers of studies about numerical investigation of structural members under impact effect in the literature (Anil et al., 2020; Delhomme et al., 2007; Kosteski et al., 2015; Mokhatar \& Abdullah, 2012; Mokhatar et al., 2013; Ranjith \& Thenmozhi, 2021).

Impact loading is a sudden dynamic loading whose intensity may be much higher than other load types. However, impact load is ignored in design phase of structural members. So, there isn't enough knowledge about behavior of materials and structural members under impact loading. Falling rock impacts, vehicle collisions, crane accidents, explosions and missile strikes are some examples of sudden impact effects. Performances of tests setups have been improved by researchers due to the regulations in ASTM E 23 that give information about limits in impact tests (ASTM E23-00, 2002). By this way, researchers have improved the performances of test setups.

When the experimental studies about impact effect in the literature are investigated, it is seen that researchers have developed drop test setups most often (Al-Rousan et al., 2017; Anil \& Yilmaz, 2015; Chakradhara et al., 2011; Erdem, 
2014; Erdem et al., 2015; Hrynyk \& Vecchio, 2014; Othman \& Marzouk, 2016; Tai \& Tang, 2006; Xiao et al., 2017; Xu et al., 2019; Zineddin \& Krauthammer, 2007). Test devices are also used to measure dynamic effects during impact tests as well as the test setup in these studies. Test setup is established to drop different magnitudes of masses from various drop heights. Thus, different levels of impact energies are applied on test members to investigate the behavior under impact loading.

As cost of the drop test setup with necessary equipment is very high and manufacturing of test specimens and completing experimental study is tiring and time consuming, some researchers prefer investigating the impact behavior of different structural members by high technology computers. So, numerical studies about impact effect have been increasing gradually in recent years (Erdem \& Gücüyen, 2017; Iqbal et al., 2019; Kishi et al., 2011; Othman \& Marzouk, 2017). However, generating accurate finite element models and performing numerical simulations of incremental dynamic analyses take a long time to reach reliable results.

In this study, it is aimed to investigate the behavior of two-way rc slabs under low velocity impact loading. For this purpose, two-way rc slabs with dimensions and reinforcement configurations are manufactured in the experimental study. Mass and drop height of the hammer are taken constant during impact experiments. Failure modes of the rc slabs are observed and advanced measurement techniques are utilized to determine time histories of acceleration, displacement and impact load values.

In the second part of the study, Abaqus finite elements analysis software (Abaqus, 2015) that is widely used by researchers to investigate the behavior of structural members under impact effect is utilized. Explicit module of the software yields reliable results for incremental dynamic analysis. It is possible to define several material models and analysis characteristics in this module. Numerical simulations of test specimens are performed by the software to verify test results. Both experimental and analysis results are comparatively presented by tables and figures and it is seen that a good correlation in behavior is established in the end.

Materials and methods

\section{Test specimens and materials}

In the scope of the experimental study, a total of 6 two-way rc slabs are manufactured in the first place. Reinforcement configuration and dimension values of the slabs are taken as the variables. Diameter of the steel bars having $420 \mathrm{MPa}$ yield strength is $6 \mathrm{~mm}$. On the other hand, mass of the hammer and drop height values are taken constant. While mass of the steel hammer that applies impact loading on rc slabs is $8 \mathrm{~kg}$, drop height is $115 \mathrm{~cm}$ in the experimental program. Properties of test specimens and experimental variables are presented in Table 1.

Table 1. Properties of the specimens. (Self-Elaboration).

\begin{tabular}{lcccc}
\hline \multicolumn{5}{c}{ Table 1. Properties of the specimens. (Self-Elaboration). } \\
sest & $\begin{array}{c}\text { Dimensions } \\
(\mathrm{mm})\end{array}$ & $\begin{array}{c}\text { Mass of the } \\
\text { hammer }(\mathrm{kg})\end{array}$ & $\begin{array}{c}\text { Drop height } \\
(\mathrm{mm})\end{array}$ & $\begin{array}{c}\text { Distance between } \\
\text { steel bars }(\mathrm{mm})\end{array}$ \\
\hline S1 & $500 \times 500 \times 60$ & 8 & 1150 & 100 \\
S2 & $500 \times 500 \times 60$ & 8 & 1150 & 50 \\
S3 & $550 \times 550 \times 60$ & 8 & 1150 & 100 \\
S4 & $550 \times 550 \times 60$ & 8 & 1150 & 50 \\
S5 & $600 \times 600 \times 60$ & 8 & 1150 & 100 \\
S6 & $600 \times 600 \times 60$ & 8 & 1150 & 50 \\
\hline
\end{tabular}

Due to high strength, reusable and resistance to water properties, plywood material is used in the manufacture of the specimens. Afterwards, lubrication operation is performed and steel bars are attached to each other by considering the distances in Table 1 and placed into the molds as shown for the Specimens 1, 3 and 5 in Figure 1.

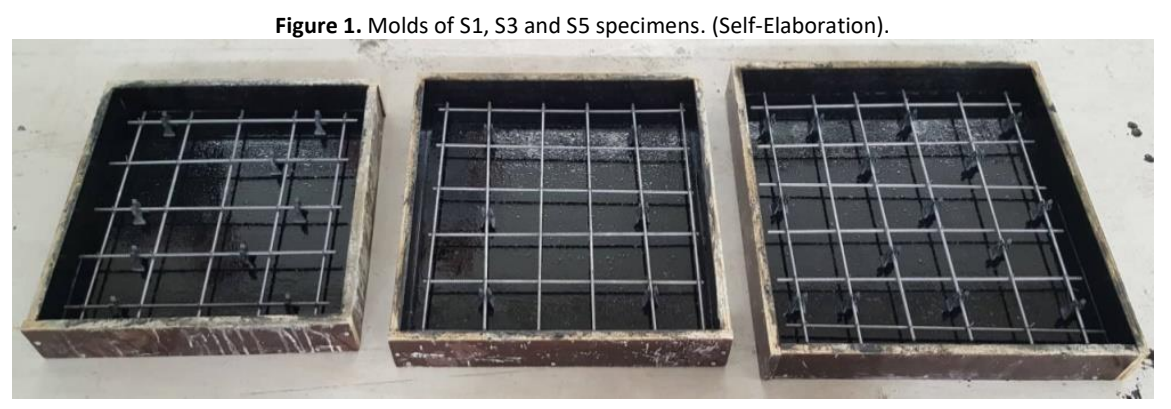


Cement, gravel, sand and water are used to produce concrete. Material amounts and percentages by weight for $1 \mathrm{~m} 3$ concrete are given in Table 2. Afterwards, necessary amounts are calculated by considering to the volume values of the molds.

\begin{tabular}{lcc}
\multicolumn{3}{c}{ Table 2. Material ratios. (Self-Elaboration). } \\
\hline Material & Amount (kg) & Weight (\%) \\
\hline Cement (42.5 R) & 350 & 14.6 \\
Gravel (0-15 mm) & 950 & 39.8 \\
Sand (0-5 mm) & 900 & 37.6 \\
Water & 190 & 8.0 \\
\hline
\end{tabular}

Concrete mixture is poured into the molds of test specimens as well as 6 cubic samples. Vibration is performed and top surfaces of the molds are straightened by a trowel. Specimens 1, 3 and 5 with cubic samples are presented in Figure 2. After completing the curing period of 28 days, the cubic samples are tested under axial load in the press machine to decide the compression strength of concrete (Lerner et al., 2020). Ultimately, average cubic compression strength value is determined as $31.7 \mathrm{MPa}$.

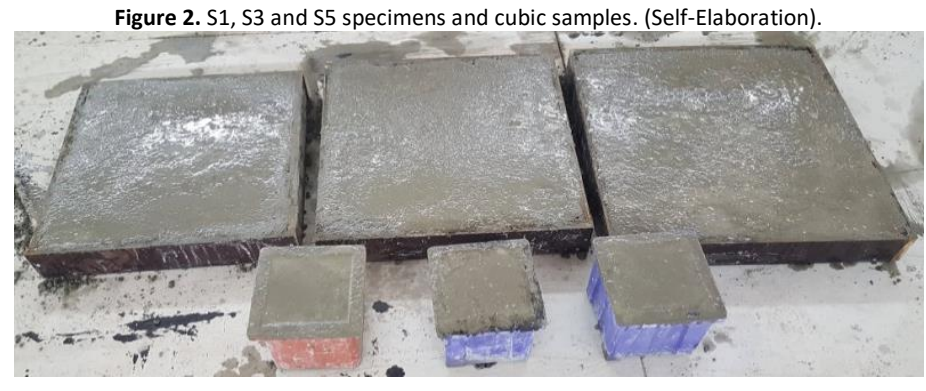

\section{Test devices}

A drop weight test setup is developed to perform impact tests on the rc slabs. This setup is able to drop masses with different magnitudes from various drop heights up to $2500 \mathrm{~mm}$. The striker also named as hammer applies impact loading on the test specimens. Besides, head part of the hammer is semispherical and it is produced from high strength steel material.

Steel hammer is placed between two slides of the test setup. Distance between the slides is $200 \mathrm{~mm}$. Base platform of the test setup is placed on a smooth surface. Steel plates are used to produce this platform whose weight is almost 500 kg.

Different measurement devices are used in the test setup to obtain experimental data during impact tests. Accelerometers, Ivdt, dynamic load cell, data-logger systems and optic photocells are the measurement devices in the experimental program. Working mechanism of the test setup with the devices is presented in Figure 3.

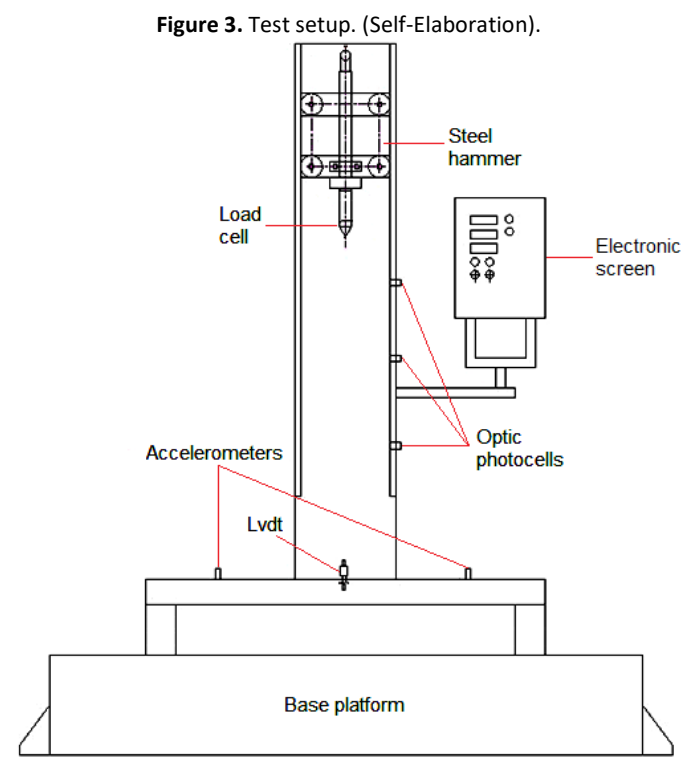


Impact energy on the test specimens is directly subjected to mass and drop height of the steel hammer. These values are selected accordingly to follow the damage developments of the specimens in the best manner. In addition, the energy level of impact loading is decided by taking the account of measurement limits of the test devices during experiments.

Combination of high strength steel plate and neoprene rubber layer having 10 and $5 \mathrm{~mm}$ thicknesses respectively are placed at impact point. By this way, local crushing is inhibited and impact loading is accurately transferred on the specimens.

Acceleration values are measured from $150 \mathrm{~mm}$ distance from impact point on test specimens. For this purpose, piezoelectric accelerometers are symmetrically placed from impact point and fixed on the specimens by brass devices. Any vibration can be measured by these accelerometers even in negative environmental conditions. While measurement range of the accelerometers is $\pm 4905 \mathrm{~m} / \mathrm{s}^{2}$, working temperature is between -18 and $+66^{\circ} \mathrm{C}$. Lvdt which is fixed to test specimens by a stick around impact point is utilized to measure displacement values of test specimens. Lvdt changes the mechanical movement of an object into electrical signals. Measurement range of lvdt is $50 \mathrm{~mm}$ with a working temperature between -18 and $+66^{\circ} \mathrm{C}$. Dynamic load cell is placed in the edge part of the hammer to determine impact load values for each drop of the steel hammer. Load cell has the capacity to determine big signals with small waves in a short time. Measurement range of the load cell is up to $88.96 \mathrm{kN}$ with a working temperature between -54 and $+121^{\circ} \mathrm{C}$.

Optic photocells are used to measure both drop durations and numbers during experimental part of this study. These values are directly seen in the electronic screen of the test setup. So, total drop numbers and drop durations are determined for each specimen. Test devices are connected to the data-logger by low noise coaxial connection cables. Thus, measurements from accelerometers, Ivdt and dynamic load cell are collected. The data-logger has 24 bit adc resolution and $12 \mathrm{vdc}$ power input with a working temperature up to $+50 \mathrm{oC}$. Measured values are transferred to datalogger in a short time of span without any loss. Afterwards, collected data is evaluated in the computer environment and time histories of acceleration, displacement and impact load values are determined in the end. A test specimen with measurement devices in the test setup is seen in Figure 4.

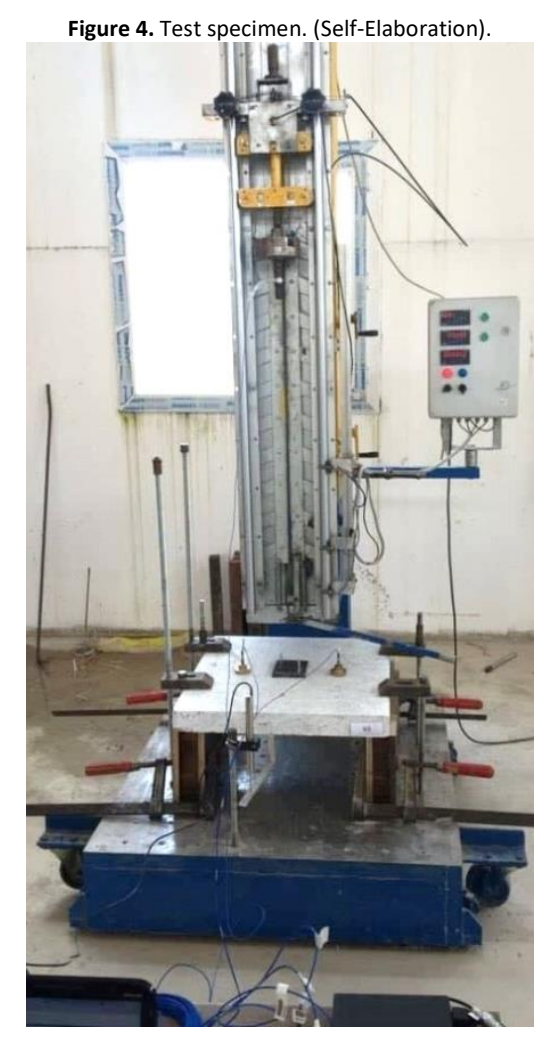

Preparations of the experimental program are completed and the specimens are tested under the constant level of impact energy by considering the values of mass of the hammer $(\mathrm{m})$, the gravitational acceleration $(\mathrm{g})$ and the drop height $(\mathrm{h})$ respectively $(8 \times 9.81 \times 1.15=90.25$ joule). Before performing impact tests on rc slabs, all test specimens are 
painted to white to trace crack developments in a better way. Afterwards, measurement devices are placed into their positions. Support conditions of the specimens are provided by support devices which are produced by steel material.

Impact tests are completed when all test specimens reach failure damage situation. Maximum displacement value is measured in failure damage situation and the specimens are not able to resist against impact loading anymore. In addition, some concrete parts fall apart from the test specimens and steel bars can be seen from the surface. Test specimens in failure damage situation are shown in Figure 5.
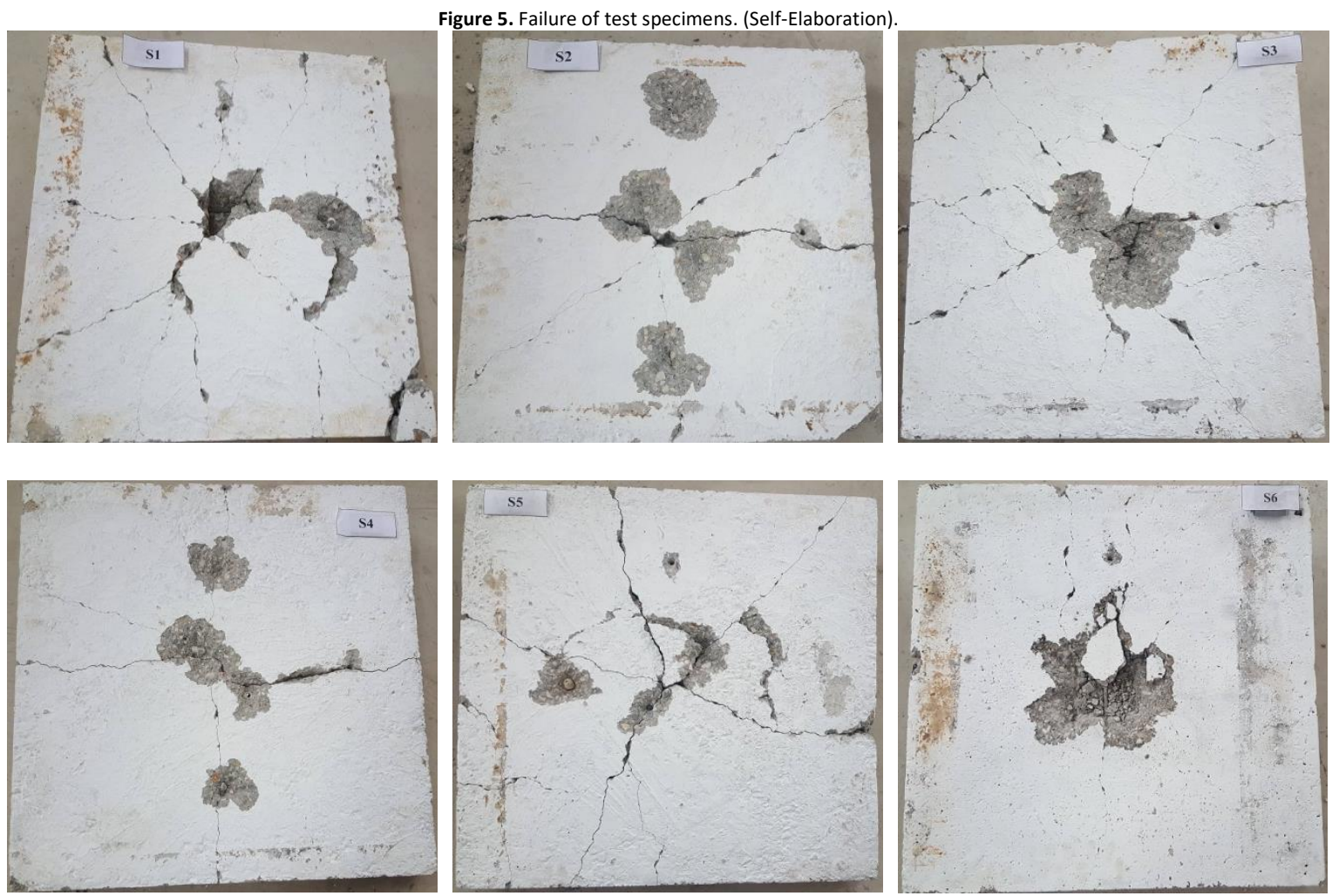

Test devices measure acceleration, displacement and impact load values for each drop of the steel hammer. Experimental values are determined until each test specimen reaches failure damage situation. Minimum and maximum accelerations that are obtained from left and right accelerometers, maximum displacements and impact loads that are obtained during experimental study are presented in Table 3.

Table 3. Experimental results. (Self-Elaboration).

\begin{tabular}{lcccccc}
\hline \multirow{2}{*}{$\begin{array}{l}\text { Specimen } \\
\text { no }\end{array}$} & $\begin{array}{c}\text { Left acceleration } \\
\left(\mathrm{m} / \mathrm{s}^{2}\right)\end{array}$ & \multicolumn{2}{c}{$\begin{array}{c}\text { Rable 3. Experimental results. (Self-Elaboration). } \\
\left(\mathrm{m} / \mathrm{s}^{2}\right)\end{array}$} & $\begin{array}{c}\text { Max. displacement } \\
(\mathrm{mm})\end{array}$ & $\begin{array}{c}\text { Max. impact load } \\
(\mathrm{N})\end{array}$ \\
\cline { 2 - 5 } & Min. & Max. & Min. & Max. & & \\
\hline S1 & -1928 & 2149 & -1765 & 2093 & 1150 & 100 \\
S2 & -2717 & 2443 & -2537 & 2154 & 1150 & 50 \\
S3 & -2293 & 2162 & -2474 & 2208 & 1150 & 100 \\
S4 & -2594 & 2917 & -2386 & 2851 & 1150 & 50 \\
S5 & -2548 & 2171 & -2671 & 2284 & 1150 & 100 \\
S6 & -3341 & 2924 & -3153 & 2842 & 1150 & 50 \\
\hline
\end{tabular}

Drop numbers and durations are determined by optic photocells in the test setup. The values are simultaneously seen in the electronic screen after the drop movement of the steel hammer. Failure drop numbers are different from each other due to reinforcement configuration and dimensions of the rc slabs. On the other hand, drop durations are similar in miliseconds owing to the constant values of the mass and drop height of the hammer in impact tests. Failure drops are determined as $34,47,41,54,45$ and 63 for the specimens respectively.

\section{Numerical study}

In this part, finite element modelling of rc slabs are generated by Abaqus software. The software is capable of performing numerical analysis under the effect of both static and dynamic loads. Therefore, engineers and researchers 
utilize Abaqus to investigate the complex behavior of structural members including high-speed collision, contact, and large deformations. The software also includes several advanced material models and failure characteristics to reach reliable results. First of all, three dimensional finite element models of the test specimens, hammer, steel plate and rubber layer are created in the software. Reinforcement configuration, dimensions of the rc slabs, mass and drop height of the steel hammer are taken similarly with the experimental study. 10 node modified tetrahedron shaped elements (C3D10M) that are appropriate for impact problems are utilized to obtain finite element models.

Supports of the specimens are defined by considering the boundary conditions for the opposite sides of the rc slabs in the software. However, movement of the steel hammer that applies impact loading on the specimens is released in vertical direction. As the problem is free fall test, only gravity force is assigned to the hammer. After constituting the finite element models, these models are separated into small pieces to obtain more accurate results. Some trials are performed to decide the proper finite element size in the software. Finally, finite element size is determined as $15 \mathrm{~mm}$ for all models. Number of the nodes and elements is given for each rc slab in Table 4. Differences between values arise from reinforcement configuration and dimensions of the slabs.

\begin{tabular}{lcc}
\multicolumn{3}{c}{ Table 4. Nodes and elements of rc slabs. (Self-Elaboration). } \\
\hline Test specimen & Nodes & Elements \\
\hline S1 & 81291 & 55850 \\
S2 & 96298 & 67202 \\
S3 & 95110 & 65502 \\
S4 & 112201 & 78378 \\
S5 & 106314 & 73162 \\
S6 & 132159 & 92643 \\
\hline
\end{tabular}

Steel hammer does not directly contact with the slabs while applying impact loading. Steel plate and rubber layer are placed and tied together on the mid-point of the slabs. Interaction property of the software is used to provide the connection between geometries. Surface to surface contact property is utilized for the surfaces of hammer and rc slabs. While surface of the hammer which applies impact loading is defined as master, surface of the specimen is defined as slave in the software. Since friction losses occur during experimental program, coefficient of friction is taken as 0.02 for the contact surfaces. Finite element model of S2 test specimen and test setup with support conditions are presented before and after mesh operation in Figure 6.

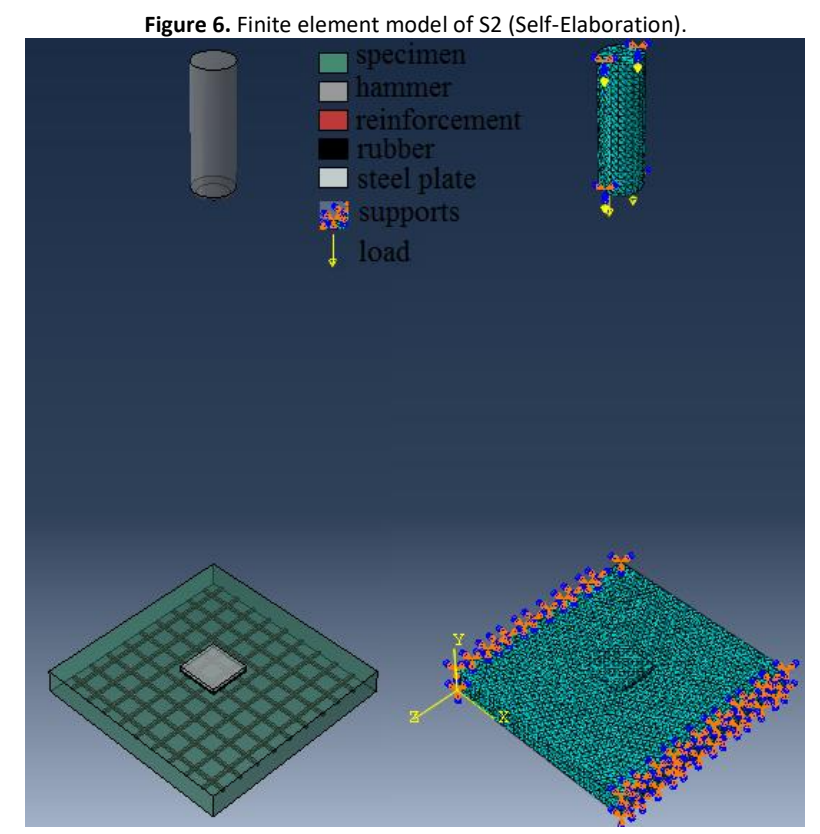

As the problem is incremental dynamic analysis, the results are highly effected by time steps and increments. Especially, small time increments have been defined in the analysis when the contact has started between the hammer and specimen (Yilmaz et al., 2018). On the other hand, it is not possible to use very small increment values due to delay in the computational period of time. So, time increments are defined as $2 \times 10-8 \mathrm{sec}$ from the contact moment. However, increment value is taken as $0.060 \mathrm{sec}$ before the contact. Numerical analysis is performed for these increments until reaching the final values. 
Next step of the numerical analysis is assigning material characteristics to the related geometries. For this purpose, properties of concrete, rubber, steel reinforcement, plate and hammer are defined in the software. Concrete damaged plasticity model that is shown in Figure 7 is utilized to define the non-linear property of concrete. This model is a continuum, plasticity-based, damage model for concrete and successfully represents the stress-strain relationship in compression and tension regions.

Figure 7. Material model for concrete. Source: Yılmaz et al. (2018).

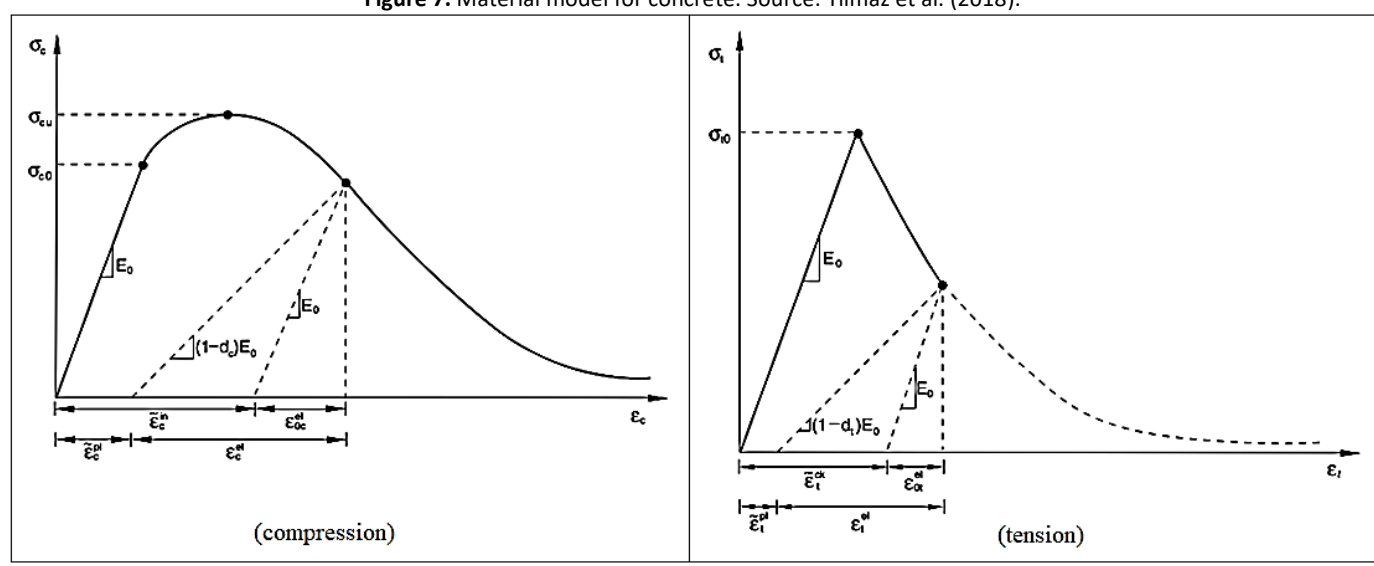

In concrete damaged plasticity model, the response is linear until reaching the value of initial yieldi $\sigma_{\mathrm{co}}$ under the effect of uniaxial compression. However, the response of concrete is specified by the stress hardening followed by strainsoftening beyond the ultimate stress, $\sigma_{c u}$ in the plastic zone. Linear elastic behavior occurs until the failure stress, $\sigma_{t 0}$ in the stress-strain relationship under uniaxial tension. This value corresponds to the start of micro-cracking occurring in the concrete. Softening stress-strain response is utilized to design the formation of micro-cracks after failure stress.

Plasticity parameters such as the dilation angle, the flow potential eccentricity, the ratio of initial equibiaxial compressive yield stress to initial uniaxial compressive yield stress, the coefficient determining the shape of the deviatoric cross-section and the viscosity are used to define the yield surface function, the potential flow and material viscosity as well as compressive and tensile behavior of concrete as defined above. These parameters are shown by $(\psi)$, $(e),\left(\sigma_{b} / \sigma_{c o}\right),\left(K_{c}\right)$ and $(\mu)$ respectively. In addition to these parameters, Poisson's ratio, density, compressive and tensile strength, modulus of elasticity of concrete are also defined in the software.

Mander's stress-strain model which is offered for unconfined concrete is used for compressive behavior of concrete (Mander et al., 1988). Value of ultimate concrete strain $\left(\varepsilon_{c u}\right)$ is taken into consideration as 0.03 . In addition, while compressive strength value of concrete is used to calculate modulus of elasticity by Equation 1 (Obaidat et al., 2010), tensile strength value is calculated by Equation 2 (Li et al., 2017). Material properties of concrete are presented in Table 5.

$$
\begin{aligned}
& E_{c}=4700 \sqrt{f_{c}^{\prime}} \\
& f_{t}^{\prime}=0.623 \sqrt{f_{c}^{\prime}}
\end{aligned}
$$

\begin{tabular}{lc}
\multicolumn{2}{c}{ Table 5. Properties of concrete (Self-Elaboration). } \\
\hline Property & Value \\
\hline Poisson's ratio & 0.20 \\
Density $\left(\mathrm{kg} / \mathrm{m}^{3}\right)$ & 2400 \\
Modulus of elasticity (MPa) & 24149.04 \\
Compressive strength (MPa) & 26.4 \\
Tensile strength $(\mathrm{MPa})$ & 3.20 \\
$\Psi$ & 30 \\
$\mathrm{e}$ & 0.10 \\
$\sigma_{\mathrm{b} d} / \sigma_{\mathrm{c} 0}$ & 1.16 \\
$\mathrm{~K}_{\mathrm{c}}$ & 0.6667 \\
$\mu$ & 0.0001 \\
\hline
\end{tabular}


The values in Table 5 are used to define the behavior of concrete in the software. Afterwards, material characteristics of steel reinforcement, hammer, plate and rubber are defined. For this purpose, linear elastic material models are used. Material properties of steel and rubber are given in Table 6.

Table 6. Properties of steel and rubber. (Self-Elaboration).

\begin{tabular}{lccc}
\hline \multicolumn{4}{c}{ Table 6. Properties of steel and rubber. (Self-Elaboration). } \\
\hline Property & Reinforcement & Hammer and plate & Rubber \\
\hline Poisson's ratio & 0.30 & 0.30 & 0.45 \\
Density (kg/m3) & 7850 & 7850 & 1230 \\
Modulus of elasticity (MPa) & 200000 & 200000 & 22 \\
Shear modulus (MPa) & 76923 & 76923 & 7.59 \\
Bulk modulus (MPa) & 166670 & 166670 & 73.33 \\
Yield strength (MPa) & 420 & - & - \\
\hline
\end{tabular}

Non-linear dynamic analyses are performed for first drop of the steel hammer. Mass and drop height of the hammer and support conditions of the rc slabs are taken in the same way with the experimental program. As the analysis requires a long period of time, a high performance computer is used for solutions. By this way, numerical results have been obtained in a faster way. Both experimental and numerical results are comparatively presented in Tables 7 and 8. Average values are also calculated to exhibit the relationship between results.

\begin{tabular}{lllllll}
\hline \multicolumn{7}{c}{ Table 7. Comparison of acceleration values. (Self-Elaboration). } \\
\cline { 2 - 6 } Specimen & \multicolumn{5}{c}{ Acceleration $\left(\mathrm{m} / \mathrm{s}^{2}\right)$} \\
\cline { 2 - 6 } no & \multicolumn{2}{c}{ Experimental } & \multicolumn{2}{c}{ Numerical } & Min. & Max. \\
\cline { 2 - 5 } & Min. & Max. & Min. & Max. & ratio & ratio \\
\hline S1 & -1928 & 2149 & -2314 & 2507 & 0.83 & 0.86 \\
S2 & -2717 & 2443 & -2735 & 2663 & 0.99 & 0.92 \\
S3 & -2474 & 2208 & -2528 & 2674 & 0.98 & 0.83 \\
S4 & -2594 & 2917 & -2962 & 2804 & 0.88 & 1.04 \\
S5 & -2671 & 2284 & -2924 & 2571 & 0.91 & 0.89 \\
S6 & -3341 & 2924 & -3158 & 3316 & 1.06 & 0.88 \\
Average & & & & & 0.94 & 0.90 \\
\hline
\end{tabular}

\begin{tabular}{lcccccc} 
& \multicolumn{6}{c}{ Table 8. Comparison of displacement and impact load values. (Self-Elaboration). } \\
\cline { 2 - 7 } Specimen & \multicolumn{5}{c}{ Displacement $(\mathrm{mm})$} & \multicolumn{3}{c}{ Impact load (N) } \\
\cline { 2 - 7 } no & Experimental & Numerical & Ratio & Experimental & Numerical & Ratio \\
\hline S1 & 3.77 & 3.94 & 0.96 & 22193 & 24518 & 0.90 \\
S2 & 3.12 & 3.36 & 0.93 & 23469 & 26737 & 0.88 \\
S3 & 3.52 & 3.40 & 1.04 & 23685 & 25953 & 0.91 \\
S4 & 2.98 & 3.19 & 0.93 & 25559 & 27875 & 0.92 \\
S5 & 3.24 & 3.16 & 1.03 & 25292 & 28063 & 0.90 \\
S6 & 2.79 & 3.02 & 0.92 & 26917 & 28429 & 0.95 \\
Average & & & 0.96 & & & 0.91 \\
\hline
\end{tabular}

Time histories of acceleration, displacement and impact load values of rc slabs are obtained by using the experimental and numerical results. Besides, impact load-displacement graphs are constituted for the same time intervals of impact load and displacement values. Acceleration-time, displacement-time, impact load-time and impact load-displacement graphs of S1, S3 and S5 specimens which have the same reinforcement configuration are comparatively shown between Figures 8 and 10 . 
Figure 8. Graphs for S1 specimen. (Self-Elaboration).
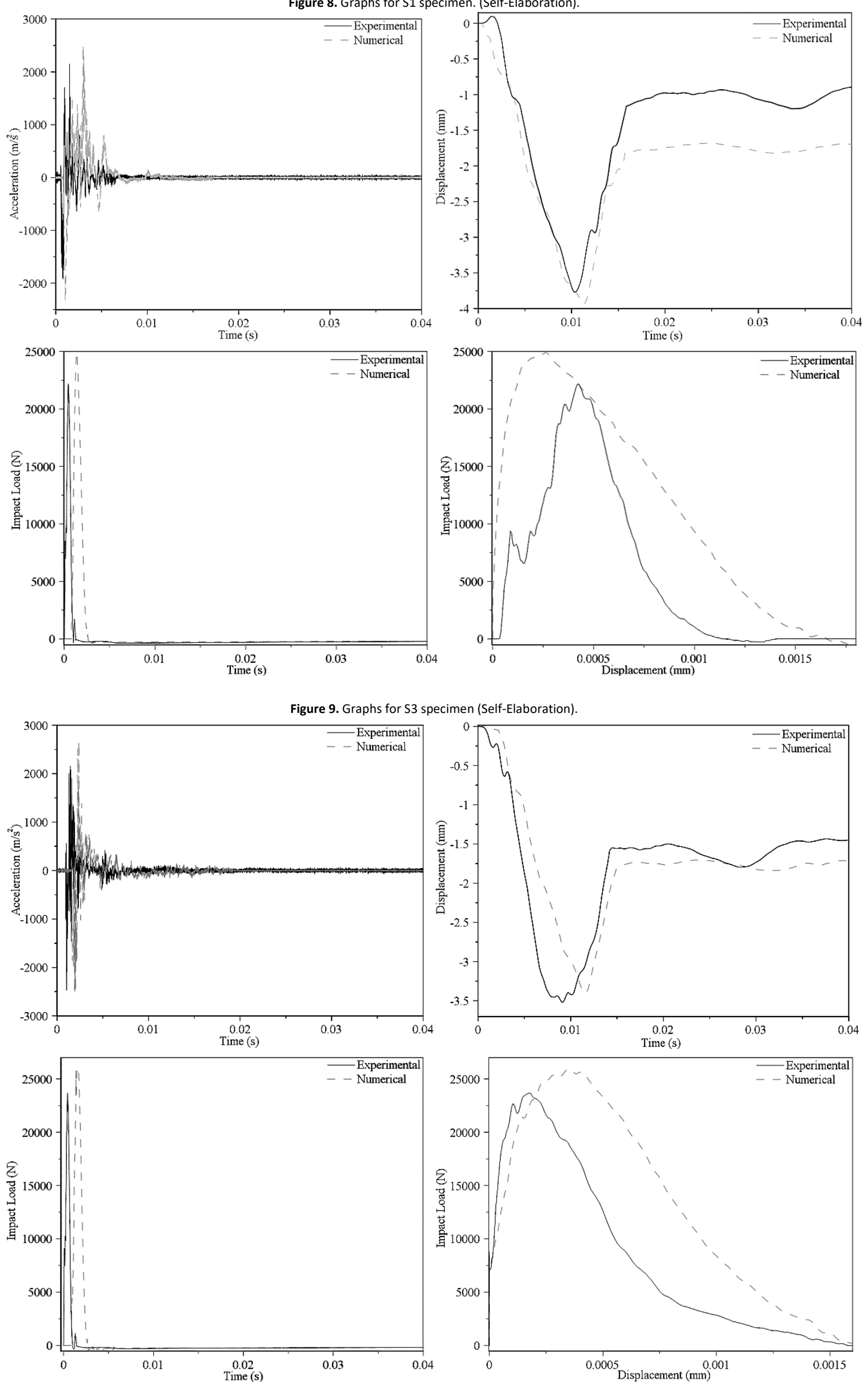
Figure 10. Graphs for S5 specimen. (Self-Elaboration).
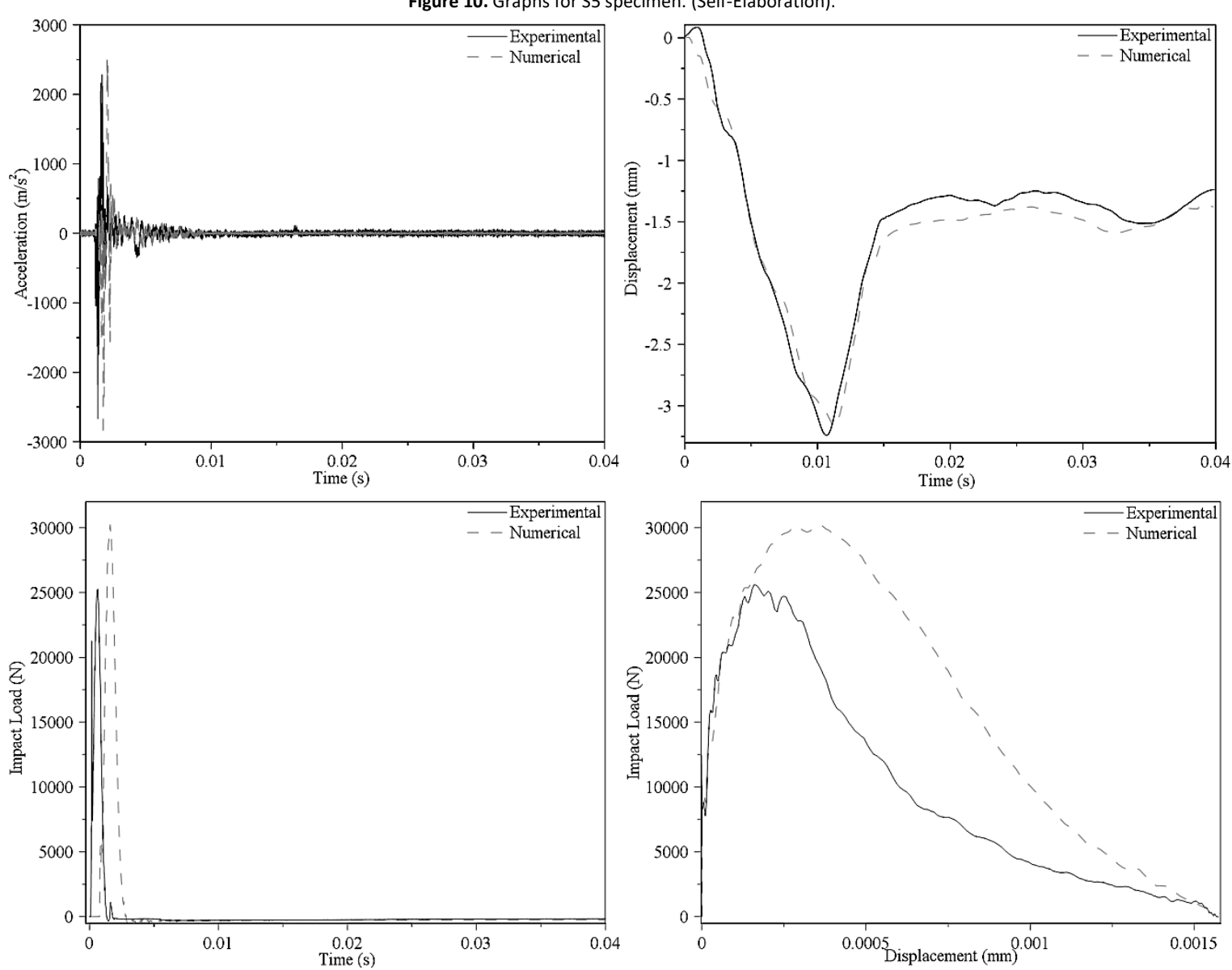

In the last step of the numerical analysis, damage patterns of the rc slabs are determined as shown in Figure 11. Damaget function of the software is utilized for this purpose. By this way, damage situations of the specimens are numerically observed after completing the experimental program. It is seen that the damages become more intense on the midpoint of the specimens where impact loading is applied and then distributes towards to the support regions.

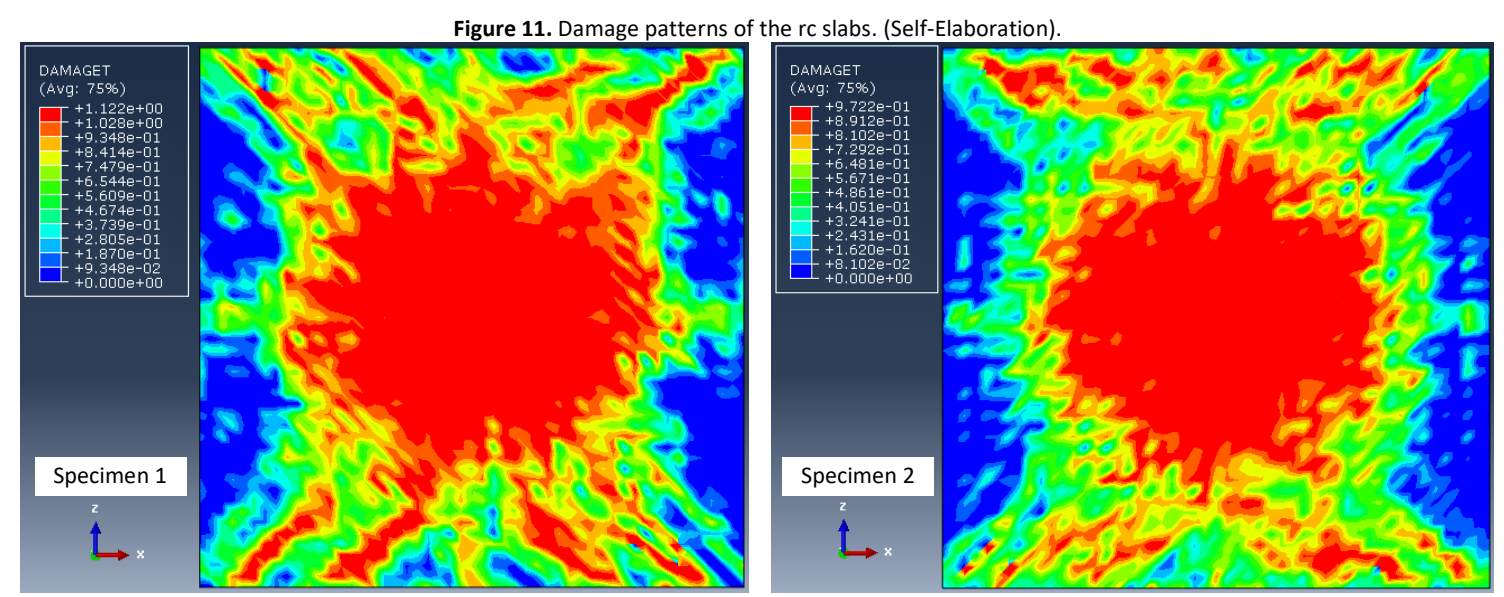



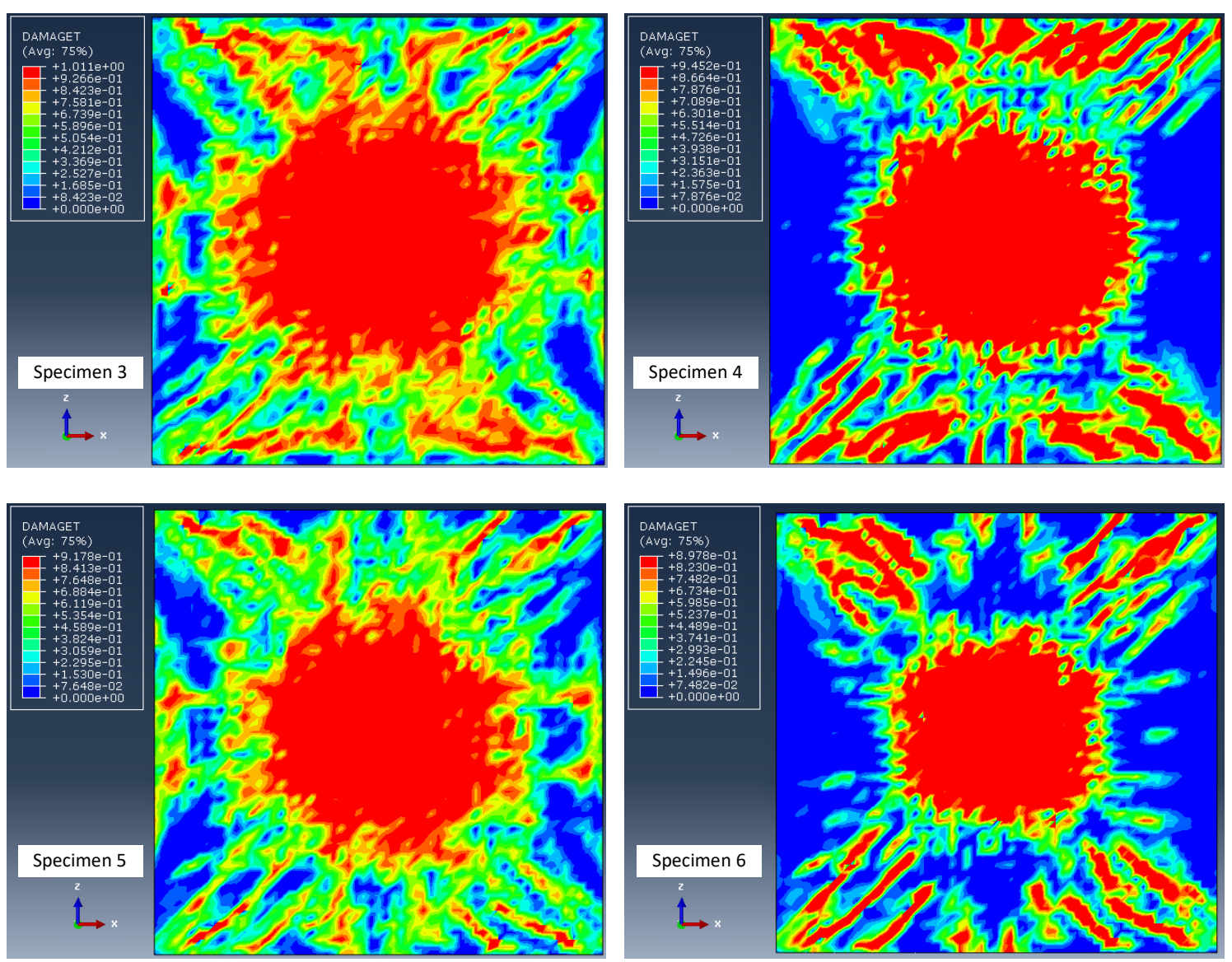

Conclusions

Rc slabs may be exposed to impact effects such as explosions, rock falls and crane accidents during their service lives. So, it is a necessity to investigate the dynamic responses, deformations and damage patterns of rc slabs under sudden impact effects. After reviewing the literature, it's seen that drop test setup is the best way to investigate the behavior of structural members under impact loading. In the scope of this study, dynamic responses of two-way rc slabs with the different dimensions and reinforcement configuration have been experimentally investigated under the constant level of impact energy. Acceleration, displacement and impact load values have been recorded until failure damage situation. In addition, non-linear incremental dynamic analysis is performed to verify experimental results.

Two piezo-electric accelerometers are symmetrically mounted on the test specimens to measure acceleration values. Greater acceleration values are obtained for the first drop of the steel hammer according to test results. In addition, stiffness and toughness of test specimens due to section sizes and reinforcement configuration affect the results. The biggest acceleration values are measured for $\mathrm{S} 6$ test specimen having the biggest dimension values but minimum distances between steel bars. Lvdt is fixed to test specimens to determine the displacement values by its spring mechanism during impact tests. Displacement values increase from the first drop of the hammer to failure damage situation of test specimens. Crack formation and decrease in the rigidity of rc slabs are main reasons of this result. The biggest displacement value is measured from the failure drop of the S1 test specimen among all. Maximum displacement values between the specimens vary between $7 \%$ and $35 \%$.

A dynamic load cell is connected to edge part of the hammer to determine impact load values during experimental study. Impact loads show tendency to decrease as the test specimens approach to failure damage situation. Besides, impact load values change with the increase of section sizes and decrease of reinforcement spacing. While maximum impact load value is determined from S6 test specimen, minimum value is measured from S1 test specimen. There is $21 \%$ difference between the impact load values of S6 and S1 specimens.

Explicit module of the software is utilized to perform non-linear dynamic simulations of rc slabs. By this way, it is aimed to verify test results by numerical analysis. Test setup and specimens are modelled in the software and analyzed under the same effects with the experimental study. Acceleration, displacement and impact load values are compared and presented by graphs. When experimental and analysis values are investigated, it's seen that a good relationship is 
established between both results. The average ratios for minimum accelerations, maximum accelerations, displacements and impact loads are calculated to be $0.94,0.90,0.96$ and 0.91 respectively. In addition, damage patterns of the rc slabs are determined from that software and consistent results are obtained in terms of crack patterns occurrence during experimental program.

It is concluded that, numerical analysis can be an option when behavior of structural members is investigated under sudden impact loading. Besides, workload in the laboratory is reduced when correct analysis procedures are followed. Although the compatibility is strong between experimental and numerical results, there are still some error rates. It is thought that friction effects, inner cracks in concrete, difficulties about providing perfect support conditions during experimental study and dynamic characteristics in the numerical analysis are the main reasons of the differences between results. Finally, due to the accordance between experimental and numerical results, it is considered that the proposed finite element procedure can be used in the calculation of dynamic responses and failure modes of the rc slabs under low velocity impact loading.

References

Al-Rousan, R. Z., Alhassan, M. A., \& Al-Salman, H. (2017). Impact resistance of polypropylene fiber reinforced concrete two-way slabs. Structural Engineering and Mechanics, 62(3), 373-380. https://doi.org/10.12989/sem.2017.62.3.373

Anil, Ö., Yilmaz, M. C., \& Barmaki, W. (2020). Experimental and numerical study of rc columns under lateral low-velocity impact load. Proceedings of the Institution of Civil Engineers: Structures and Buildings, 173(8), 549-567. https://doi.org/10.1680/jstbu.18.00041

Anil, Ö., \& Yilmaz, T. (2015). Low velocity impact behavior of shear deficient RC beam strengthened with cfrp strips. Steel and Composite Structures, 19(2), 417-439. http://dx.doi.org/10.12989/scs.2015.19.2.417

Abaqus User's Manual, Version 6.12. (2015). SIMULIA, Dassault Systèmes Simulia Corp.

ASTM E23-00. (2002). Standard test methods for notched bar impact testing of metallic materials. ASTM International, West Conshohocken, PA. https://doi.org/10.1520/E0023-00

Chakradhara R. M., Bhattacharyya, S. K., \& Barai, S. V. (2011). Behaviour of recycled aggregate concrete under drop weight impact load. Construction and Building Materials, 25(1), 69-80. https://doi.org/10.1016/j.conbuildmat.2010.06.055

Delhomme, F., Mommessin, M., Mougin, J. P., \& Perrotin, P. (2007). Simulation of a block impacting a reinforced concrete slab with a finite element model and a mass-spring system. Engineering Structures, 29(11), 2844-2852. https://doi.org/10.1016/j.engstruct.2007.01.017

Erdem, R. T. (2014). Prediction of acceleration and impact force values of a reinforced concrete slab. Computers and Concrete, 14(5), 563-575. https://doi.org/10.12989/cac.2014.14.5.563

Erdem, R. T., \& Gücüyen, E. (2017). Non-linear analysis of reinforced concrete slabs under impact effect. Gradjevinar, 69(6), $479-487$. https://doi.org/10.14256/JCE.1557.2016

Erdem, R. T., Gücüyen, E., Kantar, E., \& Bağcı, M. (2015). Impact effect on different sized reinforced concrete specimens. Indian Journal of Engineering and Materials Sciences, 22(5), 597-603.

Hrynyk, T. D., \& Vecchio, F. J. (2014). Behavior of steel fiber-reinforced concrete slabs under impact load. ACl Structural Journal, 111(5), $1213-1224$. https://doi.org/10.14359/51686923

Iqbal, M. A., Kumar, V., \& Mittal, A. K. (2019). Experimental and numerical studies on the drop impact resistance of prestressed concrete plates. International Journal of Impact Engineering, 123, 98-117. https://doi.org/10.1016/j.ijimpeng.2018.09.013

Kishi, N., Kurihashi, Y., Khasraghy, S. G., \& Mikami, H. (2011). Numerical simulation of impact response behavior of rectangular reinforced concrete slabs under falling-weight impact loading. Applied Mechanics and Materials, 82, 266-271. https://doi.org/10.4028/www.scientific.net/AMM.82.266

Kosteski, L. E., Riera, J. D., Iturrioz, I., Singh, R. K., \& Kant, T. (2015). Analysis of reinforced concrete plates subjected to impact employing the trusslike discrete element method. Fatigue and Fracture of Engineering Materials and Structures, 38(3), 276-289. https://doi.org/10.1111/ffe.12227

Lerner, L. R., Ott, M. J., Führ, L. M., Ehrenbring, H. Z. E., Pacheco, F., \& Tutikian, B. F. (2020). Influence of the molding process and different surface regularization methods on the compressive strength of concrete specimens. Revista de La Construcción. Journal of Construction, 19(1), 159-169. https://doi.org/10.7764/rdlc.19.1.159-169

$\mathrm{Li}, \mathrm{C}$., Hao, H., \& Bi, K. (2017). Numerical study on the seismic performance of precast segmental concrete columns under cyclic loading. Engineering Structures, 148, 373-386. https://doi.org/10.1016/j.engstruct.2017.06.062

Mander, J. B., Priestley, M. J. N., \& Park, R. (1988). Theoretical Stress-Strain Model for Confined Concrete. Journal of Structural Engineering, 114(8), 1804-1826. https://doi.org/10.1061/(asce)0733-9445(1988)114:8(1804)

Mokhatar, S. N., Abdullah, R., \& Kueh, A. B. H. (2013). Computational impact responses of reinforced concrete slabs. Computers and Concrete, 12(1), 37-51. https://doi.org/10.12989/cac.2013.12.1.037

Mokhatar, S. N., \& Abdullah, R. (2012). Computational analysis of reinforced concrete slabs subjected to impact loads. International Journal of Integrated Engineering, 4(2), 70-76. 
Obaidat, Y. T., Heyden, S., \& Dahlblom, O. (2010). The effect of CFRP and CFRP/concrete interface models when modelling retrofitted RC beams with FEM. Composite Structures, 92(6), 1391-1398. https://doi.org/10.1016/j.compstruct.2009.11.008

Othman, H., \& Marzouk, H. (2016). An experimental investigation on the effect of steel reinforcement on impact response of reinforced concrete plates. International Journal of Impact Engineering, 88, 12-21. https://doi.org/10.1016/j.ijimpeng.2015.08.015

Othman, H., \& Marzouk, H. (2017). Finite-element analysis of reinforced concrete plates subjected to repeated impact loads. Journal of Structural Engineering, 143(9), 1-16. https://doi.org/10.1061/(asce)st.1943-541x.0001852

Ranjith, B. B., \& Thenmozhi, R. (2021). Experimental and numerical studies on punching shear strength of concrete slabs containing sintered fly ash aggregates. Revista de la Construcción. Journal of Construction, 20(1), 15-25. https://doi.org/10.7764/RDLC.20.1.15

Tai, Y. S., \& Tang, C. C. (2006). Numerical simulation: The dynamic behavior of reinforced concrete plates under normal impact. Theoretical and Applied Fracture Mechanics, 45(2), 117-127. https://doi.org/10.1016/j.tafmec.2006.02.007

Xiao, Y., Li, B., \& Fujikake, K. (2017). Behavior of reinforced concrete slabs under low-velocity impact. ACl Structural Journal, 114(3), 643-658. https://doi.org/10.14359/51689565

Xu, X., Ma, T., \& Ning, J. (2019). Failure mechanism of reinforced concrete subjected to projectile impact loading. Engineering Failure Analysis, 96, 468-483. https://doi.org/10.1016/j.engfailanal.2018.11.006

Yılmaz, T., Kıraç, N., Anil, Ö., Erdem, R. T., \& Sezer, C. (2018). Low-velocity impact behaviour of two way RC slab strengthening with CFRP strips. Construction and Building Materials, 186, 1046-1063. https://doi.org/10.1016/j.conbuildmat.2018.08.027

Zineddin, M., \& Krauthammer, T. (2007). Dynamic response and behavior of reinforced concrete slabs under impact loading. International Journal of Impact Engineering, 34(9), 1517-1534. https://doi.org/10.1016/j.ijimpeng.2006.10.012 